\title{
Flow Modelling of Mahaweli River Reach with the Riverbed Intake of Udunuwara-Yatinuwara Water Supply Scheme
}

\author{
K. H. S. S. Karunanayake and S. B. Weerakoon
}

\begin{abstract}
The Udunuwara-Yatinuwara water supply scheme of the National Water Supply and Drainage Board abstracts water through a riverbed filtration system located in a bifurcated channel of the Mahaweli River at Peradeniya. The diverted flow through the channel has become inadequate to supply the abstraction demand during the periods of low river flow. The flow pattern in the river and the discharge through the channel are investigated by the application of a two-dimensional depthaveraged flow computational model to a $450 \mathrm{~m}$ long river reach including the channel. The model was set up, calibrated and verified for the reach using measurements carried out at the site. The model was applied to ascertain the possibility of increasing the flow through the channel during low flow in the river by changing the river bed level in the reach.
\end{abstract}

Keywords: Flow computation, modelling, water intake

\section{Introduction}

Udunuwara-Yatinuwara water supply scheme is one of the major water supply schemes of the National Water Supply and Drainage Board (NWS\&DB) providing drinking water to Udunuwara, Yatinuwara divisional secretarial divisions. At present, it serves a population of about 90,000, various institutions and industries in the area. The scheme consists of three water intakes located at Alpitiya, Nillambe and Peradeniya.

The present study is focused on the intake at Peradeniya, sited on the right bank of the Mahaweli River near the Sarasaviuyana railway station. The intake has been constructed to extract $4600 \mathrm{~m}^{3}$ of water daily into two collecting wells on the right bank of the river through two river bed rapid sand filters. River flow is bifurcated by an artificial island and one of the bifurcated flow is arranged to flow over the river bed sand filters. Filtered water is collected through perforated pipes and arranged to flow into the collecting wells. Though the intake functioned satisfactorily at the initial period after construction in 1991, the bifucated flow over the filters is not sufficient to supply the demand during low flow period of every year which is about $30 \%$ of the time at present.

Therefore, it is required to find a long term engineering solution which is economical and environmentally sound to divert adequate water to flow over the filters to enable extraction of the demand even during periods of low flow in the river. There are various options available to solve this problem; some of them are changing part of the river bed level by armouring and/or desilting, construction of groyne, spur dyke, compound weir, and weir. In this paper, only the potential of diversion of adequate flow into the bifurcated channel by changing the river bed level is investigated using computational hydraulic modelling. However, detail investigation of each option giving due considerations to all issues is required to achieve an optimum solution for implementation purpose.

Computational models for rivers are essentially based on the theoretical formulations relating the flow, fluid and geometric parameters derived by the application of conservation laws and some constitutive relationships. It is the usual practice that varying approximations, justifiable to the river flow situation in hand, are made to the model equations in order to obtain a solution with acceptable level of accuracy. Among the computational models available, one-dimensional river models based on the

K.H.S.S.Karunanayake, B.Sc.Eng. (Peradeniya), M.Sc.Eng. (Peradeniya), Engineer, National Water Supply and Drainage Board, Getemabe, Peradeniya.

Eng. (Dr.) S.B.Weerakoon, B.Sc.Eng. (Peradeniya), M.Eng. (Tokyo), D.Eng. (Tokyo), C.Eng., MIE(SL),MSLAAS, Senior Lecturer in Civil Engineering, University of Peradeniya. Peradeniya 
Saint Venant equations have been applied to river systems for gross prediction of flood water levels, discharge distributions and sediment transport along rivers. The applications of threedimensional computational studies have been limited, mostly, to laboratory channel flows with rectangular cross-sections, mainly due to the numerical instabilities encountered in the computations when the irregular boundary topography inherent to natural rivers is taken into account. On the other hand, the depthaveraged models, which are economical, are applied to shallow water rivers. The applications of depth-averaged models in Cartesian coordinates to natural rivers have been presented by ASCE [1]. Also, Wijbenga [9], Wenka et al. [8], Ye and McCorquodale, Weerakoon [6], Weerakoon et.al [7] presented applications in curvilinear coordinates which are more suitable for applications to rivers.

Objectives of this study are:

- to calibrate and validate a depth-averaged computational model to the river reach of the Mahaweli River including the river bed water intake of the Udunuwara-Yatinuwara water supply scheme, which has been planned to abstract $4600 \mathrm{~m}^{3} / \mathrm{d}$,

- predict flow pattern when the river bed level is changed, and

- to ascertain the changing of river bed level as one of the potential solution to increase diversion through the channel.

Accordingly, Surface Water Modelling System (weblink [11]) which is a two-dimensional hydrodynamic modelling system using finiteelement analysis is set up to the river reach of $450 \mathrm{~m}$ length. The validated computational model is then applied to obtain the velocity pattern and water depth under different bed topography.

\section{Computational Model}

\subsection{Governing equations}

Equations that describe the flow in surface water bodies are based on the classical concepts of conservation of mass and momentum. Depthwise integration of the momentum equations and the continuity equation with the assumption that the vertical acceleration of water is assumed to be negligible compared with the gravitational acceleration yields the depth-averaged equations applicable to shallow free surface flows (Vreguendhil and Wijbenga, [5]). The effective stress tensor components in depth-averaged equations are modelled by a gradient-diffusion model (Molls and Chaudhry [4]). The shear stress on the free surface is neglected and the bottom shear stress is modelled by relating it to the local free surface slope. Then, the local free surface slope is computed from Manning's formula. The steady state depth integrated two-dimensional momentum equations and the continuity equation are given in Eqns. (1) to (3).

$$
\begin{aligned}
& h u \frac{\partial u}{\partial x}+h v \frac{\partial u}{\partial y}+g h \frac{\partial \eta_{s}}{\partial x}-\frac{h}{\rho}\left[E_{x x} \frac{\partial^{2} u}{\partial x^{2}}+E_{x y} \frac{\partial^{2} u}{\partial y^{2}}\right]+\frac{g u n^{2}\left(u^{2}+v^{2}\right)}{h^{1 / 3}}=0 \\
& h u \frac{\partial v}{\partial x}+h v \frac{\partial v}{\partial y}+g h \frac{\partial \eta_{s}}{\partial y}-\frac{h}{\rho}\left[E_{y x} \frac{\partial^{2} v}{\partial x^{2}}+E_{y y} \frac{\partial^{2} v}{\partial y^{2}}\right]+\frac{g v n^{2}\left(u^{2}+v^{2}\right)}{h^{1 / 3}}=0
\end{aligned}
$$

$h\left\lceil\frac{\partial u}{\partial x}+\frac{\partial v}{\partial y}\right\rceil+u \frac{\partial h}{\partial x}+v \frac{\partial h}{\partial y}=0$

Here, $h=$ the water depth, $z=$ the vertical direction, $z_{b}=$ the bed elevation, $z_{s}=z_{b}+h$ is the water surface elevation, $g=$ the gravitational acceleration, $\eta_{s}=$ the water surface elevation, $\rho=$ the density of fluid, $h=$ the local water depth, $E_{i j}=$ the eddy viscosity coefficient in direction $j$ on surface I, $u=\frac{1}{h} \int_{z_{b}}^{z} u d z$ and $v=\frac{1}{h} \int_{z_{b}}^{z} v d z$ are the horizontal velocity in the $x$ direction at a point along the vertical coordinate direction and the horizontal velocity in the $y$ direction at a point along the vertical coordinate direction respectively.

\subsection{Depth-averaged Model - Surface Water Modelling System}

The Surface Water Modeling System (SMS), which is a comprehensive environment for hydrodynamic modelling includes an interface for the two-dimensional finite-element hydrodynamic model RMA2 (U.S. Army Corps of Engineers). The RMA2 hydrodynamic model is based on Eqns. (1) to (3) and iterative solution is computed for velocity and depth at discrete points in a river reach under given boundary conditions. SMS mesh module is used to construct two-dimensional finite element mesh of the river reach. The model parameters, source/sink data, and boundary conditions are assigned directly to the nodes, and elements of 
the mesh. With a mesh constructed, the RMA2 is used to compute flow velocities and watersurface elevations at each mesh node, and the boundary between wet and dry regions in the model. SMS with RMA2 model was setup to investigate the flow in a $450 \mathrm{~m}$ long reach of the Mahaweli River which includes the existing river bed water intake of the UdunuwaraYatinuwara water supply scheme.

\section{Model Calibration and Verification}

\subsection{Field Measurements}

In order to calibrate and verify the model, stream flow measurements were carried out in the river reach using the survey instruments, electromagnetic currentmeters fixed to the wading rods, and depth poles while stationed on a dingy/ boat by trained technical staff. River morphology and the bed contours in 450 $\mathrm{m}$ long river reach which includes island and the channel are shown in Fig. 1. Measurements under two different flow conditions were carried out for model calibration and verification. They correspond to river discharges of $9.7 \mathrm{~m}^{3} / \mathrm{s}$ (Case I) and $11.7 \mathrm{~m}^{3} / \mathrm{s}$ (Case II) from the upstream respectively, with an abstraction rate of $0.027 \mathrm{~m}^{3} / \mathrm{s}$ through each river bed filter. The downstream water surface elevations in Case I and II were $462 \mathrm{~m}$ and $462.11 \mathrm{~m}$ MSL respectively. The velocity measurements were carried out at discrete points along cross section (A-A), (B-B) and (C-C) (Figure 1). using an electro-magnetic currentmeter. The depths and the water surface elevations in these sections and the most downstream section of the reach were also recorded.

\subsection{Calibration}

A finite element mesh was generated to cover the reach and the model was applied to compute the velocities at the grid points when the upstream discharge was $9.7 \mathrm{~m}^{3} / \mathrm{s}$ and abstraction rate from each filter was $0.027 \mathrm{~m} 3 / \mathrm{s}$ (Case I). The boundary conditions for the computations were the upstream discharge and the downstream water calibrated for the river reach to agree the model predicted resultant velocities with the depth-averaged values of the measured velocities across a river section. This was achieved by refining the Manning's roughness coefficient (n) and the eddy viscosity () within the ranges typical to the given river reach comprising of highly rough river bed with boulders and drops (Chow [2], Wijbenga [9]). The computed results are found to be acceptable with the measured values for the $n$ value of 0.025 and eddy viscosity of $1.2 \mathrm{~m}^{2} / \mathrm{s}$. Comparison of measured and computed velocities at the river sections A-A and C-C are shown in Figures 2 and 3. Computed velocity vectors for part of the reach are shown in Figure 4.

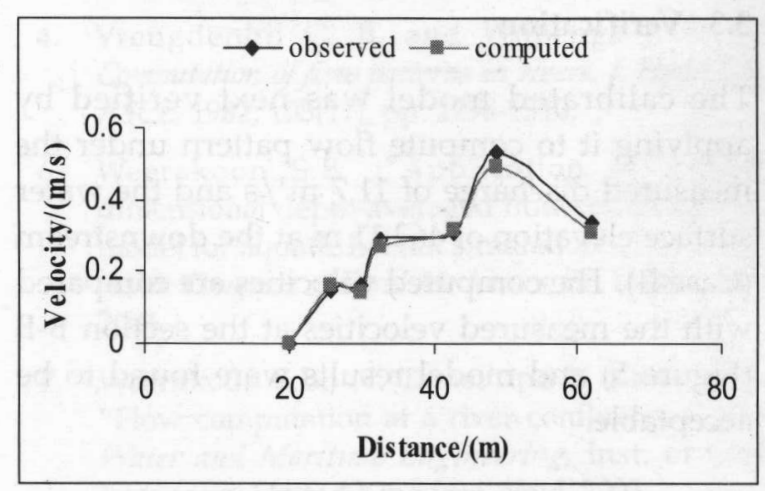

Figure 2: Comparison of Velocities at Section A-A for Case I

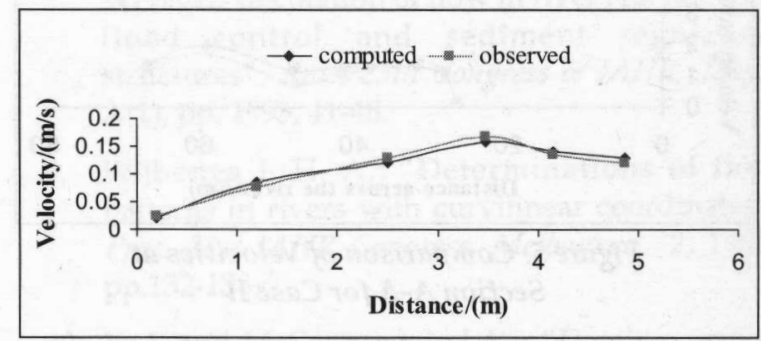

Figure 3: Comparison of Velocities at Section B-B for Case I

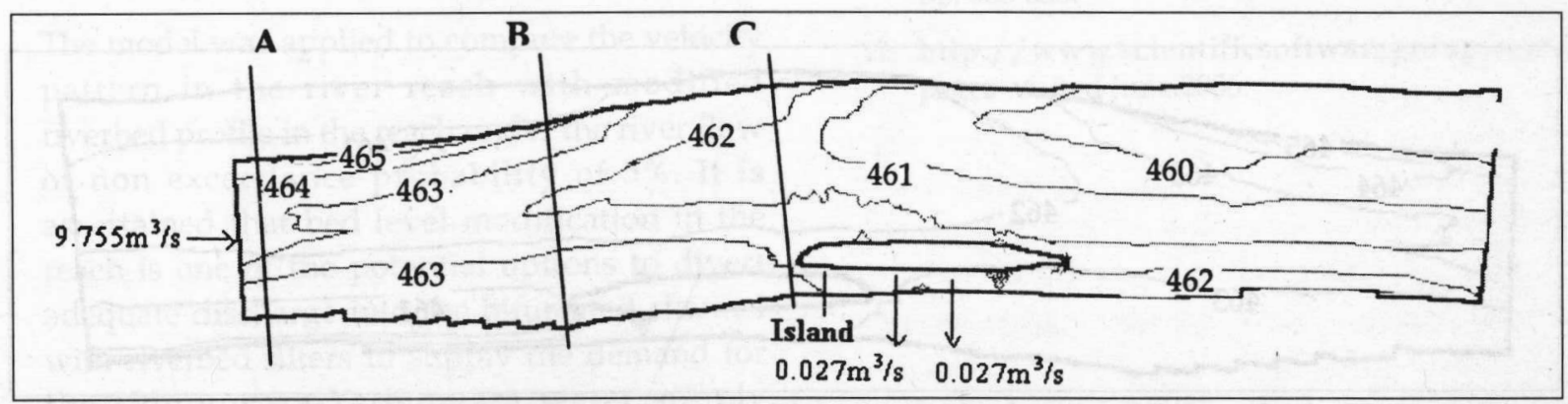

Figure 1: The Mahaweli River Reach of 450m Length, Contours are in $m$ MSL 
The independence of the predictions on the grid size was verified by carrying out the model simulations using a grid with refined mesh size under the same parameters and the boundary conditions for Case I. No changes were observed between the results of velocity and water surface elevation obtained by the two simulations, and the model results are therefore independent of the grid used for computation.

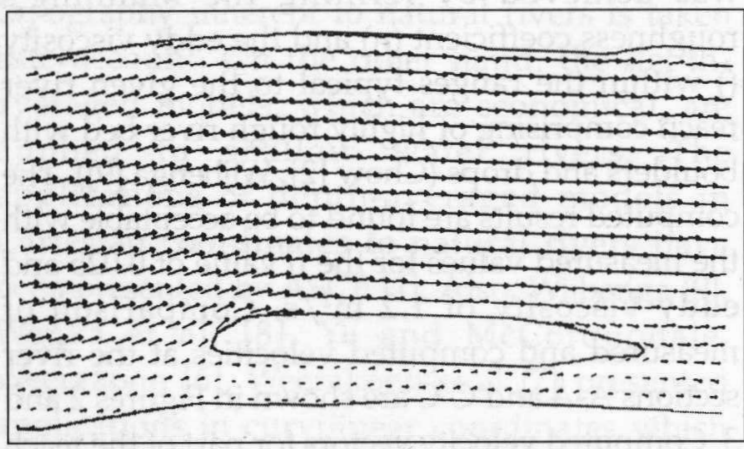

Figure 4: Celocity Vectors in Case I (Scale: $0.25 \mathrm{~m} / \mathrm{s}$ )

\subsection{Verification}

The calibrated model was next verified by applying it to compute flow pattern under the measured discharge of $11.7 \mathrm{~m}^{3} / \mathrm{s}$ and the water surface elevation of $462.11 \mathrm{~m}$ at the downstream (Case II). The computed velocities are compared with the measured velocities at the section B-B (Figure 5) and model results were found to be acceptable.

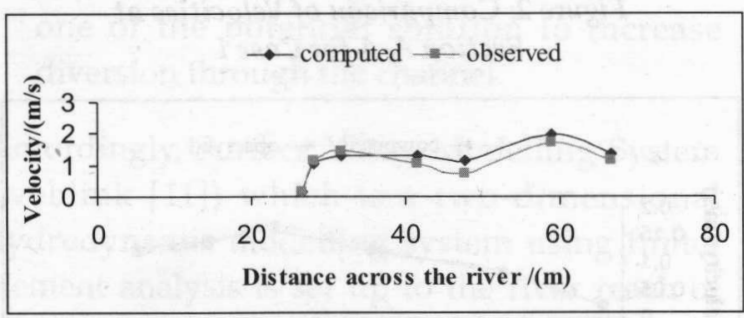

Figure 5: Comparison of Velocities at Section A-A for Case II

\section{Model Application}

The Mahaweli River flow at Peradeniya shows a significant variation due to catchment rainfall variation, diverse uses of river water and flow regulation at the upstream (Karunanayake [3]). Among them, the flow regulation by the Kotmale reservoir with a capacity of $174 \mathrm{MCM}$ impounded across the Kotmala Oya, a major tributary, is prominent. The flow in the Mahaweli River during $30 \%$ of the year fails to produce adequate flow through the bifurcated channel for the abstraction of $0.054 \mathrm{~m}^{3} / \mathrm{s}$ through the filters of the Uduuwara-Yatinuwara water supply scheme. For the purpose of present analysis the authors consider that the probability of failure of the scheme should not exceed $5 \%$. The river flow at Peradeniya. The analysis carried out using the daily flows of the Mahaweli River at Polgolla over 16 years from 1989, the river flow at Peradeniya with non exceedance probability of $5 \%$ is found to be $5 \mathrm{~m}^{3} / \mathrm{s}$.

Modification of the river bed elevation in the reach by armouring (placement of boulders or gabions) or removing silt/gravel deposits in different parts of the river bed where applicable is one of the many potential solutions listed in Section 1. The proposed bed elevation is depicted in Fig. 6 . The mean rive bed elevation in the downstream cross section in the reach is kept unaltered to minimize the river bed changes that might continue downstream. The modified bed by stacking the boulders etc. is expected to produce a less roughness to the flow than at present.

The calibrated and verified depth-averaged computational model was applied to estimate the velocity pattern for the discharge of $5 \mathrm{~m}^{3} / \mathrm{s}$ under the proposed river bed (Case III). Manning roughness coefficient of 0.021 and eddy viscosity coefficient of $1.2 \mathrm{~m}^{2} / \mathrm{s}$ were used. The downstream water surface elevation of

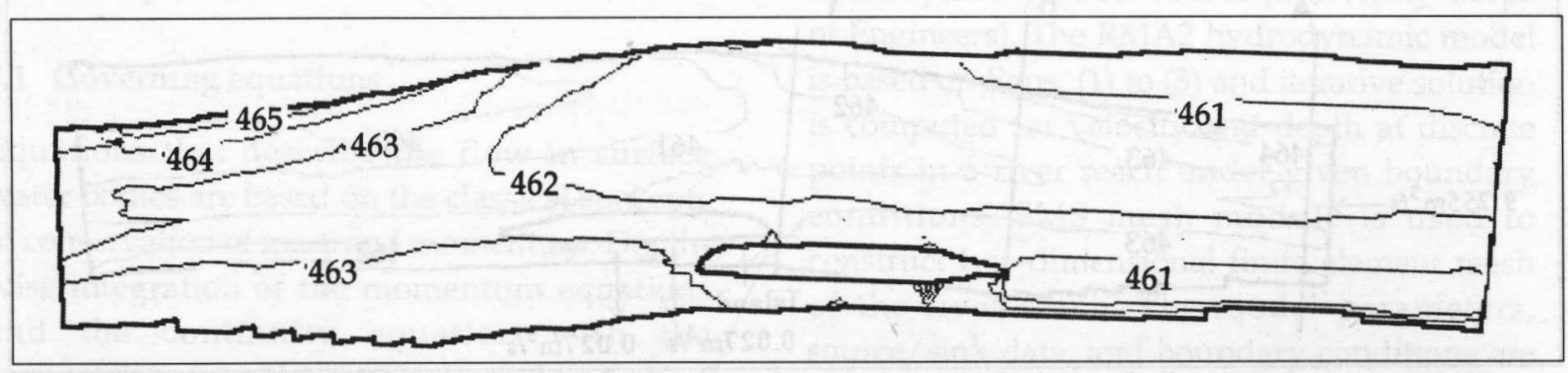

Figure 6: The Mahaweli River Reach of 450m Length with the Modified Riverbed Contours are in $m$ MSL 
461_m was based on the measurements at low flow at present. Since the mean bed level of the downstream section of the reach is unaltered this measured value is considered to be a reasonable estimate.

Computed velocity vectors for the reach are shown in Fig 7 . The discharge through the bifurcated channel becomes as $0.3 \mathrm{~m}^{3} / \mathrm{s}$ with the modified bed, whereas that at the present bed is only a tiny fraction of the demand $\left(<0.01 \mathrm{~m}^{3} / \mathrm{s}\right)$.

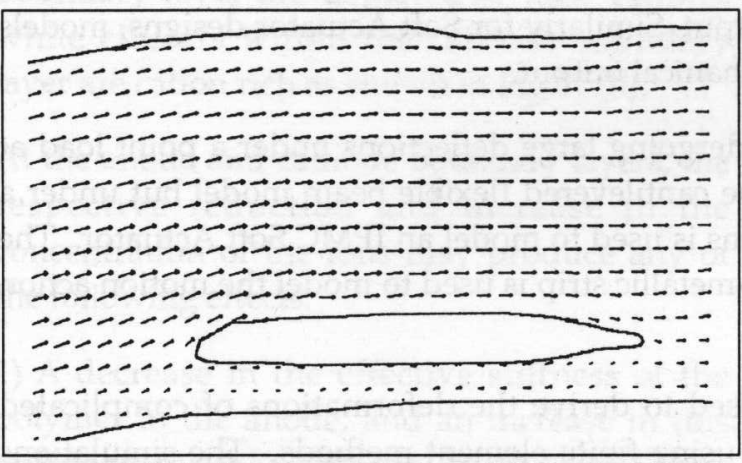

Figure 7: Velocity Vectors in Case III (Scale: $0.5 \mathrm{~m} / \mathrm{s}$ )

However detailed investigations of alternative options listed in Section 1 need to be carried out considering overall impacts. This study is limited to ascertain the riverbed modification as one of the potential options. Furthermore, even for this option the most suitable bed profile, the stable armour size need to be selected considering flood discharge and sediment transport in the reach.

\section{Concluding Remarks}

A two-dimensional depth averaged computational model was set up to the river reach of the Mahaweli River, which includes the river bed intake of the Udunuwara-Yatinuwara water supply scheme. The model was calibrated and validated using the field measurements. The model can be used to investigate flow pattern under different river flows.

The model was applied to compute the velocity pattern in the river reach with modified riverbed profile in the reach under the river flow of non exceedance probability of $5 \%$. It is ascertained that bed level modification in the reach is one of the potential options to divert adequate discharge into the bifurcated channel with riverbed filters to supply the demand for the Udunuwara-Yatinuwara water supply scheme. However, detailed investigation of each option giving due considerations to all issues is required to achieve an optimum solution before implementation.

\section{References}

1. ASCETC (ASCE Task Committee on Turbulence models in Hydraulic Computations): Turbulence modeling of surface water flow and transport. J. Hydr. Engrg. ASCE, 114(9), 1989, pp. 970-1064.

2. Chow, V. T., Maidment, D. R., and Mays, L. W.,. "Applied Hydrology", McGrew-Hill Book Company, New York, 1988.

3. Karunanayake, K.H.S.S.: "Modelling of flow in the Mahaweli River near the intake of Udunuwara-Yatinuwara water supply scheme", MScEng Thesis, Dept. of Civil Engineering, University of Peradeniya, Sri Lanka, 2007.

3. Molls T. and Chaudhry:W.H.: Depth-averaged open-channel flow model. J. of Hydraulic Engrg., ASCE, 121(6), 1995, pp. 453-465.

4. Vreugdenhil C. B. and Wijbenga J. H. A. Computation of flow patterns in rivers. J. Hydr. Div. ASCE, 1982, 108(11), pp. 1296-1310.

6. Weerakoon S.B. .: Application of a twodimensional depth-averaged flow computational model for aquatic habitat simulation", Proc. Tenth Asian Congress of Fluid Mechanics, Sri Lanka, May 2004.

7. Weerakoon S.B., N. Tamai and Y. Kawahara : "Flow computation at a river confluences", J. of Water and Maritime Engineering, Inst. of Civil Engineers, United Kingdom, Vol I, 2003.

8. Wenka Th, Rodi W. and Nestman F. : “Depthaveraged calculation of flow in river reaches with flood control and sediment regulation structures". Proc. 25th Congress of IAHR, Tokyo, A(1), pp. 1993, 41-48.

9. Wijbenga J. H. A.: "Determinations of flow patterns in rivers with curvilinear coordinates". Proc. 21st IAHR Congress, Melbourne, 2, 1985, pp.132-138.

10. Ye J. and McCorquodale J.A. : "Depth-averaged hydrodynamic model in curvilinear collocated grid". J. of Hydraulic Engrg., ASCE, 123(5), 1997, pp. 380-388.

11. http://www.scientificsoftwaregroup.com / pages visited June 2006. 